\title{
Social experience in early ontogeny has lasting effects on social skills in cooperatively breeding cichlids
}

Cornelia Arnold (cornelia.arnold@iee.unibe.ch)

Barbara Taborsky (barbara.taborsky@iee.unibe.ch)

\section{Approved by}

Ulf Dieckmann

Leader, Evolution and Ecology Program

June 2010 


\section{Contents}

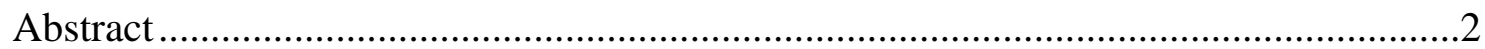

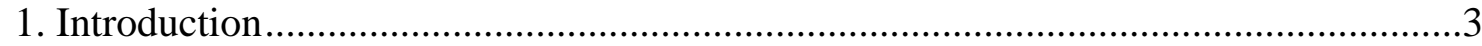

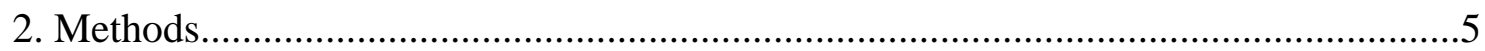

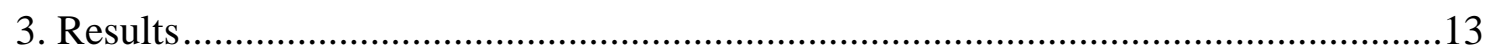

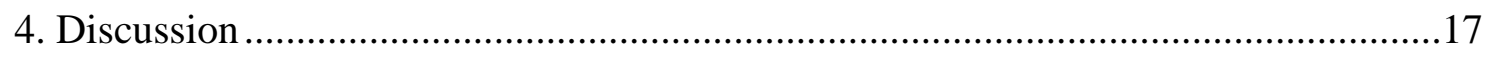

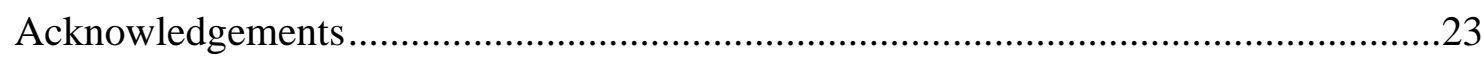

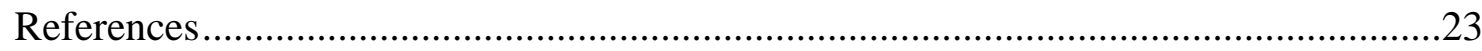

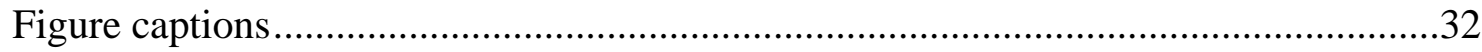


Social experience in early ontogeny has lasting effects on social skills in cooperatively breeding cichlids

\author{
Cornelia Arnold ${ }^{1} \&$ Barbara Taborsky ${ }^{1,2}$
}

${ }^{1}$ Behavioural Ecology, Institute of Ecology and Evolution, University of Bern, Switzerland

${ }^{2}$ Evolution \& Ecology Program, IIASA, Austria

Running headline: Social experience affects social skills in fish

Correspondence:

Barbara Taborsky

Department of Behavioural Ecology

Institute of Ecology and Evolution

University of Bern

Wohlenstrasse $50 \mathrm{~A}$

CH-3032 Hinterkappelen

Switzerland

barbara.taborsky@iee.unibe.ch

phone: +41 3163191 57; fax: +41 316319141

Institutional address of C. Arnold: same as correspondence address 


\section{Abstract}

The early social environment can affect the social behaviour of animals throughout life. Here we tested whether the presence of adults during early development influences the social behaviour of juveniles later on in the cooperatively-breeding cichlid Neolamprologus pulcher. In a split-brood design we raised half of the broods together with parents and with or without brood care helpers, and the other half without adults. During early rearing fry raised with adults displayed more aggressive and submissive behaviour amongst each other than fish raised with siblings only. After transferring the young to a neutral environment lacking adult conspecifics we tested their social performance in a competitive situation. Young were either assigned the ownership of a shelter or had no shelter of their own. As shelter owners, fish that had been raised with adults showed more of an energetically cheaper, restrained form of aggression, while as intruders they behave more often submissively, than fish raised without adults. The strength of these treatment effects depended on the opponent's social experience, and contests were terminated earlier only when both opponents had been raised with adults. Our results show that the social raising conditions persistently affect the economy and adequacy of individual reactions to social challenges, which is reminiscent of social competence effects known from humans. Remarkably, during the social treatment period brood care only involves protection but no direct interactions between adults and young. We discuss potential mechanisms by which the presence of brood caring adults may persistently affect social skills in animals.

Keywords: early environment, ontogeny, social skills, aggressive behaviour, submissive behaviour, cooperative breeder, cichlids 


\section{Introduction}

The social environment experienced during early development can have a crucial influence on the social behaviour of animals throughout their life (e.g. Laviola \& Terranova 1998). In species with brood care, the early social environment consists predominantly of parents and siblings. Effects of social experiences in the natal family are well documented on behavioural and physiological responses until adulthood in rodents and primates, including humans (e.g. Bastian 2003, Levine \& Mody 2003, Meaney \& Szyf 2005, Bester-Meredith \& Marler 2007, Niles et al. 2008). Such long-term effects can be demonstrated, for example, by depriving an experimental group of the contact with certain family members during ontogeny. Animals raised without parents may show a variety of severe deficits in emotional regulation and social interactions (Bertin and Richard-Yris 2005) and a reduced ability of social learning (Lévy et al. 2003). Long-lasting effects of early socialization can have a strong impact on fitness. For example in birds and fish, the early social environment can play an important role for finding appropriate mating partners during adulthood (e.g. Adkins-Regan \& Krakauer 2000, Verzijden \& ten Cate 2007). Subadult mice lacking opportunities for contact with younger sibling pups suffered from a severely reduced reproductive success when becoming mature (Margulis et al. 2005). Conversely, an enrichment of the post-natal social environment can improve the offspring's ability to respond adequately to social challenges (D'Andrea et al. 2007).

On the proximate level such long-term effects on social behaviour can be mediated through changes in hormone production and secretion and in the sensitivity to hormones and neuropeptides during neural development (reviewed in Cushing \& Kramer 2005). For example, the mammalian hypothalamic-pituitary-adrenal (HPA) axis, which is the major neuroendocrine system to control reactions to social and environmental stress, is highly 
plastic and known to be permanently modified by early experiences (Levine \& Mody 2003). In addition, during the juvenile development of learning and memory patterns the opportunity to learn from social interactions can trigger the acquisition of life-long social skills (e.g. Del Guidice et al. 2009).

The effects of early social environment have been studied mainly in humans and mammalian and avian model species, in which brood care usually involves intensive parentoffspring interactions. Many other animals, particularly in aquatic habitats, only defend their offspring against predators and do not engage in direct interactions with their young. For example, in Neolamprologus pulcher, a cooperatively breeding cichlid with a highly advanced social system, parents and brood care helpers guard the brood against predators and they have direct contact only with eggs and larval stages when cleaning them from microbial parasites (Taborsky 1984). Parents and helpers form a complex, size-dependent and sexspecific social hierarchy (Taborsky \& Limberger 1981, Taborsky 1984, Mitchell et al. 2009). It is conceivable that group members must dispose of well-developed social skills to behave appropriately in their respective social roles, as inadequate behaviour can result in eviction from the safe territory (Taborsky 1985), which is detrimental (Taborsky 1984, Heg et al. 2004). We tested if the early social environment experienced in the natal family influences the development of social skills in these fish, even in the absence of direct social interactions with older family members.

As for the mechanism behind a potential experience effect, we focused on two alternative hypotheses and tested the different predictions derived from them. (1) Older family members may influence the social skills of developing young by affording protection, which might reduce their need of being vigilant. This may increase the interaction frequencies between siblings and corresponding opportunities to learn from such interactions. In this case 
young with older family members, regardless of the precise family composition, should interact more frequently amongst each other and, consequently, be able to solve social tasks better. (2) Developing young may obtain direct social cues from older family members, in which case young should posses better social skills the more complex the family composition was during early ontogeny. We tested these predictions by raising $N$. pulcher fry at three levels of social complexity, (i) in the absence of socially experienced, older individuals, (ii) with parents only and (iii) with parents and subadult helpers. After independence, we confronted the young fish to an asymmetric competitive situation.

\section{Methods}

Study species

Neolamprologus pulcher is a highly social cichlid endemic to Lake Tanganyika, East Africa living in family groups that defend small territories around breeding cavities (Taborsky 1984; N. pulcher is synonymous with N. brichardi; Duftner et al. 2007). Family units typically consist of a breeding pair, 1-14 immature and mature brood care helpers (mean=5 helpers, Balshine et al. 2001) and offspring. N. pulcher lays clutches of 100-200 eggs, which are attached to the walls of the breeding shelter (Taborsky 1982). Within nine days after hatching young develop into free-swimming fry. Brood care of eggs and larvae involves fanning to improve oxygen supply, removal of microorganisms by 'mouthing' and removing sand from shelters to prevent sedimentation of offspring. Offspring are guarded and protected against predators during the entire early development from the egg stage until the juvenile period (Taborsky 1984, Balshine et al. 2001, Brouwer et al. 2005). Direct contact between offspring and parents or helpers is hence restricted to the egg and larval stages that end nine days after hatching. While smaller helpers predominantly help to clean eggs, larvae and the 
breeding cavity, larger helpers join in defence against conspecific and interspecific space competitors and predators (Taborsky 1982). Helpers may be related or unrelated to the breeders (Dierkes et al. 2005). By staying in their natal territory they mainly benefit from protection against predators (Taborsky 1984, Balshine et al. 1998, Heg et al. 2004). They pay rent for being allowed to stay in the territory by joining in brood care (Taborsky 1984, 1985, Balshine-Earn et al. 1998, Bergmüller et al. 2005, Bergmüller and Taborsky 2005).

Housing conditions

The experiment was conducted at the Ethologische Station Hasli of the Institute for Ecology and Evolution, University of Bern, Switzerland, under license 40/05 of the Veterinary Service of the Kanton Bern. The parents of our experimental fish were laboratoryreared second and third generation offspring of fish originating from the southern end of Lake Tanganyika near Mpulungu, Zambia. All experimental fish were reintegrated in our institute's breeding stock after the end of the experiments.

Each experimental clutch was produced in a separate 200-1 breeding tank. These tanks were equipped with a 2-cm sand layer, eight flowerpots halves arranged in a half circle serving as shelters and breeding cavities. Two PET bottles halves placed closely below the water surface provided additional shelter. Two internal biological filters on each side of a tank were shielded from the main water body by a PVC plate to prevent fish from using them as breeding shelter. The light:dark cycle was set to 13:11 hours with 10 minutes dimmed light periods in the morning and evening to simulate the light conditions at Lake Tanganyika. Water temperature was held constant at $27 \pm 1^{\circ} \mathrm{C}$ and the biochemical parameters were kept close to values of southern Lake Tanganyika (B. Taborsky, unpubl. data). Fish were fed $a d$ libitum six days a week ( $5 \mathrm{~d}$ commercial flake food, $1 \mathrm{~d}$ frozen zooplankton). 


\section{Experimental design}

Six males and six females above $60 \mathrm{~mm}$ standard length (SL) haphazardly chosen from stock tanks were assigned to form six breeding pairs conditional on males being larger than females to mimic natural size relations (c.f. Taborsky 1984, Balshine et al. 2001). Each breeder pair raised two experimental clutches in succession. For their first experimental clutch, each of three breeder pairs received two unrelated helpers, a small (19-21 mm SL) and a medium sized one (29-31 mm SL), while the other three breeder pairs received two helpers during the production of the second experimental clutch. The sex of all helpers was unknown, since it cannot be reliably determined in $N$. pulcher at these body sizes.

Only clutches with more than 40 eggs were used for the experiment. Smaller clutches were removed at the day of egg laying. At day 10 after hatching, when the offspring were free-swimming, all fry were temporarily removed, the breeding tank was divided with a tight opaque partition into two equally-sized compartments, and the fry were distributed equally over the two compartments. Throughout this paper, experimental days are given on a scale starting at the day of brood-splitting (=day 0; Fig. 1). Splitting of clutches resulted in similar group sizes in the two compartments throughout a trial (despite occasional losses by mortality), but between trials group sizes varied because of initial clutch sizes differences (range over all compartments: 8-42 fry).

During the 2 months following brood-splitting ('social experience phase'), one half of the clutch was kept together with the breeder pair (with or without helpers) and the other half was kept alone (Fig. 1). The position of breeders in either the left or right compartment of the breeding tank was balanced between trials. We refer to the two sibling groups by the social 
environment they experienced during the social experience phase period, namely 'with breeders' $(+\mathrm{B})$, 'with breeders and helpers' $(+\mathrm{BH})$, 'without breeders' $(-\mathrm{B})$ and 'without breeders or helpers' $(-\mathrm{BH})$. When the behaviour did not differ between $+\mathrm{B}$ and $+\mathrm{BH}$ fish or between $-\mathrm{B}$ and $-\mathrm{BH}$, we combined the two treatments with older family members present and the treatments with offspring growing up alone, refereeing to them as ' $+\mathrm{F}^{\prime}$ and ' $-\mathrm{F}$ '.

At the end of the social experience phase on day 62, all groups of same-treatment siblings were transferred to separate 45-1 holding tanks. Groups remained in these tanks for 35 days ('neutral phase', Fig. 1). On day 62, we also removed the partitions from the breeding tanks and let the breeding pairs access the entire 200-1 tank for the production of the second experimental clutches. Overall, 24 groups of same-treatment siblings (termed 'treatment groups') resulted from our experimental design.

\section{Morphological measurements}

We monitored the growth of experimental offspring by measuring length (SL) and weight every 14 days starting at day 36 (twice during the social experience phase, once shortly after transferring the offspring, and twice during the neutral phase; Fig. 1). To select the fish for these measurements, ten fry of each treatment group were chosen with help of random numbers (generated by Microsoft Office Excel 2003). The shoal of fry was counted starting alternately from left, right, top or bottom of the tank, and the fry in the position of the random number was captured for measuring. If the group size was $\leq 10$, all fry were measured. SL was estimated to the nearest $0.5 \mathrm{~mm}$ by placing the fry on a measuring board with a 1.0 mm grid. For weighing, fry were placed on a moist cotton pad to prevent damage of their body surface and gills. Weights were read to the nearest $0.0001 \mathrm{~g}$. We calculated specific 
growth rates as $\left(\ln \mathrm{SL}_{2}\right.$-ln $\left.\mathrm{SL}_{1}\right) /\left(\operatorname{age}_{2}\right.$-age $) \times 100$, where $\mathrm{SL}_{1}$ and $\mathrm{SL}_{2}$ are the mean standard lengths of two successive measurements, and Fulton's condition factor as K=weight/SL ${ }^{3} \times 100$.

Observations during the social experience phase

Offspring. From day 35 after brood-splitting onwards, when fry had an approximate length of $1 \mathrm{~cm}$, we recorded the behaviour of fry four times (referred to as 'repeats'; one repeat every 7th day). We observed 10 fry per treatment group when the group size was $>15$ and 5 fry for group sizes $\leq 15$ (170 fry in total). Focal individuals were selected with help of random numbers following the same procedure as when choosing fry for size measurements (see above). After a habituation period of $3 \mathrm{~min}$, when the observer (CA) was sitting motionless in front of the tank, each focal fish was observed for 5-min.

Seven social behaviours out of the complex behavioural repertoire of $N$. pulcher (see ethogram in Taborsky 1982) were recognized in the fry: 'frontal approach', 'chase', 'ramming', 'biting' and 'bow swimming' were later combined as 'aggressive behaviour', while 'tail quiver' and 'hook display' were combined as 'submissive behaviour' (following the classification of Taborsky 1982, 1984). In addition, we recorded two non-social behaviours, 'feeding' (taking up a food item) and 'swimming' (moving without performing a social behaviour). All behaviours were recorded as frequencies. We used mean frequencies of the fry of the same treatment group for statistical analysis. To estimate the overall activity of focal fish, we subdivided the water body of a compartment in 12 virtual, equally sized cuboids $(25 \times 20 \times 12 \mathrm{~cm})$ and counted each time when a fish crossed the virtual borders between cuboids. The borders of the cuboids were visualised by markings located at the front screen and the sandy bottom of the tank. 
Breeders and helpers. The behaviour of breeders and helpers was recorded in the same way as in fry. In addition to the behaviours performed by fry, adults showed 'head down display' and 'fin spreading', which represent restrained aggression and will be referred to as 'threat display' (Taborsky 1982). Observations took place directly after the observations of fry (see above).

Social performance test

At day 97, about one month after the young had been transferred to a neutral environment (Fig. 1), we tested the social performance of fish. By this time, young had reached a size at which in nature they would usually act as helpers of dominant breeders, but they were not yet sexually mature. We tested sets of two fish in an asymmetric, competitive situation, as pilot trials had revealed that in a symmetric setting with both fish in the role of an owner of the same resource young did not engage in competitive interactions at all. Experimental tanks of $30 \times 20 \times 20 \mathrm{~cm}$ size were divided into two equal compartments, one of which contained a shelter (a dome-shaped piece of PVC of $2 \mathrm{~cm}$ radius, $4 \mathrm{~cm}$ in length) and the other one was empty. One fish was assigned the role of the shelter 'owner' and was placed in the compartment with the shelter, the other one, the 'intruder', was placed in the empty compartment.

From each of the 12 experimental clutches, four size-matched pairs of contestants (maximum length difference $0.5 \mathrm{~mm} \mathrm{SL}$ ) were selected, each consisting of a $+\mathrm{F}$ and $\mathrm{a}-\mathrm{F}$ treatment sibling. Same size fish are not necessarily of identical weight. We selected the sizematched pairs such that the heavier contestant was always assigned the role of the intruder to increase its potential chances for a territory takeover. Members of each pair of contestants were marked by cutting a tiny piece (about $2 \mathrm{~mm}$ long) of the filaments of either the top or 
bottom tip of the tail fin. We used four different experimental tanks. In two tanks, the $+\mathrm{F}$ fish was assigned to be the territory holder, in the other two tanks it was the $-\mathrm{F}$ fish. Behavioural frequencies (submission, open aggression and threat behaviour, time of retreat) were not correlated between siblings of the same treatment group tested in the same social role (all $\mathrm{p}>0.2, \mathrm{~N}=24$, Pearson correlations) allowing us to use each trial as independent data point. Additional contests between size-matched pairs of fish with the same social treatment ( 8 pairs of $+\mathrm{F}$ fish, 8 pairs of $-\mathrm{F}$ fish) were conducted. In these trials, we combined individuals from different families to avoid possible biases due to familiarity. In total 64 contest trials were performed.

Fish were allowed to habituate to the experimental set-up over night. The next day, shelters were always occupied by the 'owner'. In nature, access to shelters is limited and it is critical for survival. Therefore 'intruders' were expected to try hard to get access to the only shelter available in our experimental set-up. After removing the partitions from the experimental tanks, we observed the two contestants for 20 min from the moment when one of them had crossed the virtual border between the two compartments. The compartment borders were visualised by markings at the front screen and by a groove in the sandy bottom of the tank. To avoid any influence of the observer on the behaviour of the test fish, observations were done behind a black curtain through an observation slit. All social behaviours were recorded continuously in the sequence of occurrence, and combined in the categories 'aggressive behaviour', 'threat display' and 'submissive behaviour' analogous to the observations of fry. At no time during the trials fish were at risk to be injured, as due to the asymmetric roles of the contestants aggression never resulted in escalated fights. In the rare cases where aggression involved body contact (biting or ramming) this did not result in injuries of the body surface due to the low impact of these behaviours in fish that weigh between only 0.2 and $0.3 \mathrm{~g}$. Additionally, we recorded the position of both young in the water 
column once per minute by virtual division of the water column in equal thirds. Contests were considered to be terminated when one fish retreated either to the upper parts of the water column or to a distant corner of the tank, where it was safe from attacks by the shelter owner. Fish could reach these safe sites within fractions of a second. Once retreated a fish usually remained there until the end of the 20 min observation period. In some cases it returned after the contest had been interrupted for several minutes, but was then quickly driven away again by the shelter owner. We analyzed only the interactions between the start and the end of a contest. As the duration of these periods varied between trials, we analysed behavioural rates $\left(\mathrm{min}^{-1}\right)$ rather than total frequencies of behaviour.

The position of the shelter was balanced between left and right compartments to control for possible side effects. However, neither the rate of aggressive behaviour of territory holders $(\mathrm{z}=1.37, \mathrm{p}=0.17)$, nor the rate of submissive behaviour of intruders $(\mathrm{z}=1.22, \mathrm{p}=0.22)$ differed between test fish placed in the left or the right compartments (Wilcoxon matchedpairs signed-ranks tests, $\mathrm{N}=32$ ).

Data analysis

Analyses were done with R 2.6.0 (R Development Core Team 2006) using the lme4 package (Bates 2007) and with SPSS 17.0 for Windows. We built generalized linear mixedeffects models (GLMM) to analyse the aggressive behaviour of fry, linear mixed-effects models (LME) to analyse SL and Fulton's condition factor K using R. In these models, we tested for the significance of a fixed effect by comparing the model containing the fixed effect with the model without fixed effects with a likelihood ratio test (Faraway 2006). Model choice was based on the p-values provided by the randomisation tests. When the fixed effect had more than two levels and a significant overall effect was found, we performed pair-wise 
comparisons between levels and corrected for multiple testing by sequential Bonferroni correction. We analysed growth rates and aggressive behaviour of experienced family members using the LME module of SPSS. The identity of breeding pair and clutch was included in all mixed models. Data on submissive behaviour of both fry and experienced fish were highly zero-inflated, and were therefore analyzed by Wilcoxon matched-pairs signedranks tests. All statistical tests are two-tailed.

\section{Results}

Size, body condition and growth. The raising conditions affected the body size (SL) of young (Table 1, Fig. 2). Post-hoc comparisons of SL between treatments revealed that fry raised with breeders and helpers $(+\mathrm{BH})$ were significantly smaller than young raised without older fish ( $-\mathrm{B}$ and $-\mathrm{BH}$ fry, referred to as $-\mathrm{F}$ fry), while there was no difference between $+\mathrm{B}$ and $-\mathrm{F}$

siblings (Table 1). These differences existed already at day 36 after the onset of the social experience phase (i.e. at the smallest possible size when young can be handled) and persisted over the entire measurement period until day 92. This is indicated by the absence of a significant interaction between treatment and repeated measures. Moreover, specific growth rates did not differ between treatments, neither in the period before (measurement 1 to measurement 2, LME: $\mathrm{F}=0.049, \mathrm{p}=0.95, \mathrm{~N}=195$ ) nor after the transfer to the $45-1$ holding tanks (measurement 3 to 5 , LME: $\mathrm{F}=0.40, \mathrm{p}=0.68, \mathrm{~N}=193$ ). There was also no significant effect of treatment, repeat or the interaction between these factors on Fulton's condition factor (LME: all p>0.1, N=986).

Social experience phase 
Activity of fry. Mean swimming activity did not differ between $+\mathrm{B}$ and $-\mathrm{B}$ or between $+\mathrm{BH}$ and $-\mathrm{BH}$ fry and there was also no effect of repeat on swimming activity (LME: all p $>0.1$, $\mathrm{N}=47$ ).

Aggressive behaviour of fry. Treatment and repeats affected the aggressive behaviour of fry during the social experience phase interactively (Table 2). During the last of the four repeated observations, aggressive behaviours occurred more often in the two treatments with older family members being present $(+\mathrm{B}$ and $+\mathrm{BH})$ than in groups raised without older fish (significant after sequential Bonferroni correction, Table 2), whereas there was no difference between $+\mathrm{B}$ and $+\mathrm{BH}$ fish (Fig. 3a shows the combined results of $+\mathrm{B}$ and $+\mathrm{BH}$ [referred to as $+\mathrm{F}]$ vs. $-\mathrm{B}$ and $-\mathrm{BH}$ fry $[$ referred to as $-\mathrm{F}])$.

Submissive behaviour of fry. Submissive behaviour did not differ between young raised alone $(-\mathrm{F})$ or with older family members $(+\mathrm{F})$ in repeats 1 and 2 , while in repeat 3 and $4,+\mathrm{F}$ fish behaved more often submissively than $-\mathrm{F}$ fish (Table 3; Fig. 3b). When analysing the data separately by treatments with $(+\mathrm{BH}$ vs $-\mathrm{BH})$ or without helpers $(+\mathrm{B}$ vs $-\mathrm{B})$, submission frequencies differed in repeat 3 , but not 4 .

Behaviour of breeders and helpers. Notably, breeders and helpers never interacted directly with any of the fry. As the interactions among older family members might indirectly influence the behaviour of young, we compared (i) the total frequencies of interactions among older family members between the $+\mathrm{B}$ and $+\mathrm{BH}$ treatments (more interactions expected when there are four rather than two fish) and (ii) the social behaviour shown by breeders only when helpers were present or absent (more social behaviour by breeders expected when helpers are present). The total frequency of aggression was higher in $+\mathrm{BH}$ treatment groups (Table $4 \mathrm{a}$ ). Apparently, this effect was not predominantly caused by the larger number of older family 
members in these groups (4 vs. 2), but rather by an increased amount of aggressive behaviour exhibited by the breeders in the presence of helpers (Table $4 \mathrm{~b}$ ). Total submission tended to be higher with helpers present in repeat 1 , (Wilcoxon test: $\mathrm{z}=1.89, \mathrm{p}=0.06 ; \mathrm{N}=6$ ), but no other differences in submission appeared between $+\mathrm{B}$ and $+\mathrm{BH}$ treatments in any other repeat (all $\mathrm{p}>0.1)$

Social performance test

$B$ vs. BH treatment. In the social performance test, none of the behavioural rates differed between $+\mathrm{B}$ and $+\mathrm{BH}$ fish or between $-\mathrm{B}$ and $-\mathrm{BH}$ fish (Wilcoxon tests: all $\mathrm{p}>0.2, \mathrm{~N}=12$ ) Therefore we combined $+\mathrm{B}$ and $+\mathrm{BH}$ fish as $+\mathrm{F}$ fish and $-\mathrm{B}$ and $-\mathrm{BH}$ fish as $-\mathrm{F}$ fish in all further analyses.

Behaviour of intruder. Intruders of the $+\mathrm{F}$ treatment showed submission at a faster rate (Table 5). As we were interested in the adequate use of submissive displays, we also tested if $+F$ showed more submissive behaviours relative to the aggression they were exposed to by shelter owners, although this parameter is not entirely independent of the rate of submission. This relative measure was also higher in $+\mathrm{F}$ than in $-\mathrm{F}$ intruders (Table 5). Remarkably, the differences in the rates of submission (Fig. 4a) and submission relative to the amount of received aggression (Fig. 4b) are mainly due to interactions in which also the opponent (shelter owner) had been raised in a $+\mathrm{F}$ environment (Table 5), while these traits did not differ between $+\mathrm{F}$ and $-\mathrm{F}$ intruders when the shelter owner had been raised in $-\mathrm{F}$ conditions.

Generally, aggressive behaviour by intruders occurred only rarely (threat displays/min: median[quartiles] $=0.078[0,0.14]$; open aggression $/ \mathrm{min}=0.067[0,0.25]) .+\mathrm{F}$ intruders showed 
higher rates of threat displays (Wilcoxon test: $\mathrm{z}=2.07, \mathrm{p}=0.038, \mathrm{~N}=31$ ), while rates of open aggression did not differ (Wilcoxon test: $\mathrm{z}=0.059, \mathrm{p}=0.55 ; \mathrm{N}=31$ ).

Behaviour of shelter owner. $+\mathrm{F}$ shelter owners showed higher rates of threat displays, whereas rates of open aggression did not differ between $+\mathrm{F}$ and $-\mathrm{F}$ shelter owners (Table 5). Calculating the proportions of the two types of aggressive behaviour revealed that $+\mathrm{F}$ fish showed relative more threat display and, accordingly, less open aggression than $-\mathrm{F}$ fish (Table 5). Only once an initial shelter owner displayed submissive behaviour. This was one of the few cases when the initial shelter owner lost the shelter during the trial (see below).

The social experience of both opponents also mattered for the occurrence of threat displays. If the intruder had been raised with older family members, $+F$ shelter owners displayed higher rates of threat behaviour (Table 5, Fig. 4c) and showed proportionally more threat behaviour (Table 5) than $-\mathrm{F}$ shelter owners did. None of these traits differed between $+\mathrm{F}$ and $-\mathrm{F}$ shelter owners, however, when the opponent had had been raised in the $-\mathrm{F}$ treatment (Table 5). Rates of open aggression by shelter owners did not differ between treatments even when separating the analyses by the raising conditions experienced by intruders (both $\mathrm{p}>0.5 ; \mathrm{N}_{1,2}=24+8$ ).

Duration of contests. In $92.2 \%$ of the trials the initial shelter owner won the contests and the intruder retreated from the vicinity of the shelter. In five trials the intruder won the contest. In all these cases the initial shelter owner was a -F fish. In those cases when the shelter owner won, the duration of contests was shorter if the shelter owner was $\mathrm{a}+\mathrm{F}$ than when it was $\mathrm{a}-\mathrm{F}$ fish $\left(\mathrm{U}=293.5, \mathrm{p}=0.035, \mathrm{~N}_{1,2}=32,27\right.$, U-test). Also the duration of contests depended on the social background of both opponents. The time until the outcome of a contest was decided was significantly shorter for $+\mathrm{F}$ shelter owners than for $-\mathrm{F}$ shelter owners when the intruder 
was a $+\mathrm{F}$ fish, whereas there was no difference in time of retreat between contests when the intruder was a -F fish (Fig. 4d).

Overall, intruders tended to retreat earlier when exposed to higher rates of threat display by shelter owners (Spearman rank correlation: $\mathrm{r}_{\mathrm{S}}=-0.24, \mathrm{p}=0.069, \mathrm{~N}=59$ ), while rates of open aggression by shelter owners, or the rates of submission by intruders did not predict the time of retreat (Spearman rank correlations: both $\mathrm{p}>0.4$ ). When analyzing $+\mathrm{F}$ and $-\mathrm{F}$ intruders separately, the effects of aggression on time to retreat were more pronounced. $+\mathrm{F}$ intruders retreated earlier when they were exposed to higher rates of aggression by shelter owners (threat display: $r_{S}=-0.37, p=0.050 ;$ open aggression: $r_{S}=-0.36, p=0.053 ; N=29$ intruders that lost) while neither aggression by shelter owners nor submission shown by intruders was related to time of retreat in $-\mathrm{F}$ intruders (Spearman rank correlations: all $\mathrm{p}>0.2$, $\mathrm{N}=30$ ).

\section{Discussion}

Our data show that the social environment during rearing influences the social behaviour later in life in the cooperatively breeding cichlid N. pulcher. Young that had been raised with older family members, either with parents only or with parents and helpers, showed more appropriate behaviours in response to their experimentally assigned social roles than young raised in same age sibling groups only. To test for the effect of social experience, we chose a test simulating a situation juvenile fish encounter in natural territories, where they defend a private shelter against other juvenile family members (Werner et al. 2003). Shelter owners raised with adults performed more threat displays and intruders of the $+\mathrm{F}$ treatment showed more submissive behaviours than young raised with sibmates only, whereas none of 
the groups differed in their propensity to show open aggression. These effects were detected one month after the experimental fish had been separated from the older family members, and all young had been transferred to a new environment. Hence any direct influence of older, socially experienced fish can be excluded on the outcome of these social performance tests.

Several results indicate that $+\mathrm{F}$ fish did not only show certain behaviours more often, but they had acquired also better social skills. (1) $+\mathrm{F}$ fish adjusted their behaviour to the social context. In the role of the shelter owner, $+\mathrm{F}$ young showed more of a restrained and hence energetically cheaper form of aggression (threat displays), which is an adequate response of a dominant individual to defend a resource when the social challenge is moderate as it was the case in our asymmetric test situation. Also restrained aggression made up a higher proportion of total aggression in $+\mathrm{F}$ fish than in $-\mathrm{F}$ fish. (2) In N. pulcher contests, submission is usually shown in response to an aggressive approach by a conspecific. When in the role of the intruder, $+\mathrm{F}$ fish responded more often by submission when being attacked than $-\mathrm{F}$ intruders did. (3) The strength of effects caused by the rearing environment depended strongly on the social experience of the opponent in the trials. When confronted with a $+\mathrm{F}$ fish, $+\mathrm{F}$-shelter owners showed more threat behaviour and they won contests faster, whereas + F-intruders showed more submission than $-\mathrm{F}$ fish did, while there was no treatment effect if the opponent was a -F fish. Possibly, showing adequate role-specific behaviours allows to resolve conflicts more quickly.

The behavioural differences observed between treatments indicate that $+\mathrm{F}$ fish behave in a way that reduces the potential costs of contests. Overt aggression may result in an overt backlash by the attacked opponent and subsequent escalation. By showing more threat behaviour instead of overt attacks, more submissive behaviour when in the inferior role and earlier retreat socially experienced fish may minimize the risk of escalated contests thereby 
reducing energetic expenditure (e.g. see Earley et al. 2006) and risk of injury. The ability to display submission to reduce the aggression of dominant group members (e.g. Bergmüller and Taborsky 2005) is especially important in cooperatively breeding species such as N.pulcher, where it is crucial for the survival of young to be accepted as helpers in group territories (Taborsky 1984, 1985). Performing submissive behaviour in $N$. pulcher comes at a high cost however, as it raises the routine metabolic rates of the fish by factor 3.3 (Grantner and Taborsky 1998).

Social behaviour started to diverge between the treatments at weeks 7 and 8 , i.e. towards the end of the social experience phase. Fry kept together with older family members were more aggressive and showed higher frequencies of submissive behaviour than fry kept with siblings only. This might be a critical phase in the development of the fish determining the social behaviour throughout life. Several mechanisms may be responsible for the increase in of social behaviour of $+\mathrm{F}$ fry at the end of the social experience phase. Interactions of the older family members amongst each other might have caused an increased activity in the small fry, resulting in a higher probability of meeting each other. We can exclude this possibility, however, as activity levels did not differ between $+\mathrm{F}$ and $-\mathrm{F}$ fish. Further we can exclude that the effects are caused by learning from direct interactions with the older family members, as fry only interacted with siblings. However, the presence of breeders and helpers could have modulated fry behaviour through eavesdropping, a form of social learning that is known to influence foraging choices (Brown and Laland 2003) and predator recognition (Kelley and Magurran 2003) in fish. It is unlikely that fry are able to observe and correctly interpret the complex social behaviour of parents and helpers, i.e. fish that are not directly interacting with fry. This task would seem to be too complex given that the neural machinery is probably still poorly developed in these small young. It is possible, though, that various stimuli produced by interacting adults are perceived by the fry more or less inadvertently, like 
acoustic (Amorim et al. 2004) and olfactory (Hirschenhauser et al. 2008) cues during certain activities of adults. This might be associated with each other (e.g. pheromone release and interaction context) and result in some form of conditioning of the developing brain.

There are potential alternative mechanisms, however, to explain the higher propensity of $+\mathrm{F}$ fry to show social behaviour. (i) The safe environment provided by the protection of breeders might allow fry to engage more frequently in peer-interactions, thereby enhancing the potential for social learning from these interactions. Fry growing up alone may spend more time being vigilant, hence constraining time for social interactions. (ii) Effects on social behaviour might also be induced indirectly by the organizational action of water-borne hormones produced by adult fish (Earley et al. 2006). $+\mathrm{F}$ fry were constantly exposed to adult hormone excretion, while $-\mathrm{F}$ fish are lacking this experience. Both mechanisms are consistent with our finding that the presence or absence of older fish $(+\mathrm{F}$ vs. $-\mathrm{F})$ rather than the complexity of the family structure (+BH vs. +B vs. $-\mathrm{BH} /-\mathrm{B})$ influenced offspring social behaviour.

The different early social environments did not affect the growth rates of fry, apart from a very early growth advantage of $-\mathrm{BH}$ fish over their $+\mathrm{BH}$ siblings that took apparently place before we could take the first size measurements (the time of the first measurement was constrained by a minimum size needed for handling fry). This size difference remained until the last size measurements at the age of three months. We assigned the larvae to their treatment groups in a fully randomized procedure, so that we are confident that the size differences at the first measurement are not an experimental artefact. Differential activity levels can also not explain the size differences, as locomotory activity did not differ between treatments. The early growth differences between $+\mathrm{BH}$ and $-\mathrm{BH}$ treatment groups are hence not straightforward. It is unlikely that food availability explains this effect, as larvae and fry 
received a different type of food than breeders and helpers. Alternatively, the presence of helpers in addition to breeders resulted in higher levels of aggression among the older family members of these groups, which might have acted as a stressor for the fry resulting in reduced growth (e.g. Jentoft et al. 2005). Finally, growth of fry in $+\mathrm{BH}$ groups might have been affected by the higher biomass present per compartment, which may have resulted in growth inhibition through a higher concentration of metabolites in the water (e.g. Pinto et al. 2007). All these mechanisms, however, imply the occurrence of differential growth rates of treatment groups throughout the social experience phase, which was not the case.

Long-term effects of the early social environment on social behaviour have been demonstrated in several vertebrates (e.g. fish, Moretz et al. 2007; birds, Adkins-Regan \& Krakauer 2000, Bertin \& Richard-Yris 2005, rodents, Bester-Meredith 2007; primates Bastian et al. 2003; humans, reviewed in Meaney \& Szyf 2005). For example, parenting style affected the amount of reconciliation of young rhesus macaques (Macaca mulatta, Waal \& Johanowicz 1993) and aggression in California mice pups (Peromyscus californicus, BesterMeredith 2007) when cross-fostered with related, more tolerant species. In mammals effects of the early rearing environment on social behaviour and stress responsiveness are often mediated through tactile stimuli during parental care and their downstream effects on hormonal excretion and expression of receptors in the brain (Champagne \& Curley 2005, Frazier et al. 2006). Mother-reared and peer-reared rhesus macaques acquired a higher social rank than young raised with limited access to conspecifics (Bastian et al. 2003) indicating that long-lasting effects of early social environment can affect fitness. The mechanisms responsible for the effects of early social experience found in N. pulcher ought to be different, however, because direct interactions between adults and offspring during brood care do not occur. We are not aware of previous studies investigating the effects of parental care on offspring social behaviour in fish. In different social contexts not involving parental care, 
however, long-term effects of the early social environment have been reported in fish. Zebra

551 fish Danio rerio, had a long-lasting increased aggressive propensity when kept as juveniles in groups of mixed strains (Moretz et al. 2007) and guppies raised in high densities had a lower shoaling tendency and a reduced social learning ability later on (Chapman et al. 2008).

Our experimental set-up involved social deprivation/enrichment at three levels, absence of older family members, parents being present and parent and brood care helpers being present. In mammals, social deprivation (e.g. being raised with peers only, Kempes et al. 2008) and enrichment (e.g. communal nesting, D’Andrea et al. 2007) affected social skills. The suite of improved social skills observed in $N$. pulcher raised with older fish is reminiscent of the four key axes along which human social competence can be measured (Dierks et al 2007). According to Dirks et al. (2007), social competence is both (1) a trait of an individual (here we tested siblings raised in identical environments rather than the same individuals in different roles) and (2) characterized by certain behaviours (e.g. restrained aggression and submission are more adequate and efficient behaviours than open aggression and flight behaviour in an asymmetric competitive situation as staged in our performance test); in addition, it is (3) situation-specific (shelter owners vs. intruders in our case) and (4) 'judgespecific', i.e. a certain behaviour is perceived differently by different classes of conspecifics (which would require receiver-specific adjustments of behaviour as observed in our fish). Moreover, social competence requires some sort of success measure of appropriate behaviour (see Dirks et al. 2007). Indeed in N. pulcher, (i) contests were shortest when both opponents had been raised in more complex family groups and (ii) fish raised with older fish used behaviour more economically (e.g. they showed more relatively more restrained than open aggression), which should reduce their energy expenditure. It is conceivable that social competence is similarly important for individuals living in complex animal societies as it is for humans. 


\section{Acknowledgements}

We thank Michael Taborsky for valuable input and sharing his extensive knowledge on our study system with us during all stages of this study, Christoph Grüter for help with statistical analyses and Evi Zwygart for assistance in maintaining the study animals. B.T. was funded by the Swiss National Science Foundation (SNF, Project 3100A0-111796) and the Austrian Science Fund (FWF, Project 18647-B16).

\section{References}

Adkins-Regan, E. \& Krakauer, A. 2000. Removal of adult males from the rearing environment increases preference for same-sex partners in the zebra finch. Animal Behaviour, 60, 47-53.

Amorim, M.C.P., Knight, M.E., Stratoudakis, Y. \& Turner, G.F. 2004. Differences in sounds made by courting males of three closely related Lake Malawi cichlid species. Journal of Fish Biology, 65, 1358-1371.

Balshine-Earn, S., Neat, F.C., Reid, H. \& Taborsky, M. 1998. Paying to stay or paying to breed? Field evidence for direct benefits of helping behavior in a cooperatively breeding fish. Behavioral Ecology, 9, 432-438.

Balshine, S., Leach, B., Neat, F., Reid, H., Taborsky, M. \& Werner, N. 2001. Correlates of group size in a cooperatively breeding cichlid fish. Behavioral Ecology and Sociobiology, 50, 134-140.

Bastian, M.L., Sponberg, A.C., Suomi, S.J., Higley, J.D. 2003. Long term effect of infant rearing condition on the acquisition of dominance rank in juvenile and adult rhesus macaques (Macaca mulatta). Developmental Psychobiology, 42, 44-51.

Bates, D. 2007. Ime4: Linear mixed-effects models using S4 classes. R package version 0. 99875-7.

Bergmüller, R., Heg, D., Peer, K. \& Taborsky, M. 2005. Extended safe havens and between-group dispersal of helpers in a cooperatively breeding cichlid. Behaviour, 142, 1643-1667.

Bergmüller, R., Taborsky, M. 2005. Experimental manipulation of helping in a cooperative breeder: helpers 'pay to stay' by pre-emptive appeasement. Animal Behaviour, 69, 19-28.

Bertin, A., Richard-Yris, M.A. 2005. Mothering during early development influences subsequent emotional and social behaviour in Japanese Quail. Journal of Experimental Zoology, 303A, 792801.

Bester-Meredith, J.K., Marler, C.A. 2007. Social experience during development and female offspring aggression in Peromyscus mice. Ethology, 113, 889-900. 
Brouwer, L., Heg, D. \& Taborsky M. 2005. Experimental evidence for helper effects in a cooperatively breeding cichlid. Behavioral Ecology, 16, 667-673.

Brown, C. \& Laland, K.N. 2003. Social learning in fishes: a review. Fish and Fisheries, 4, 280-288.

Champagne, F. \& Curley, J.P. 2005. How social experiences influence the brain. Neurobiology, 15, 704-709.

Chapman, B.B., Ward, A.J.W. \& Krause, J. 2008. Schooling and learning: early social environment predicts social learning ability in the guppy, Poecilia reticulata. Animal Behaviour, 76, 923-929.

D'Andrea, I., Alleva, E. \& Branchi, I. 2007. Communal nesting, an early social enrichment, affects social competences but not learning and memory abilities at adulthood. Behavioural Brain Research, 183, 60-66.

Del Guidice, M., Angeleri, R. \& Manera, V. 2009. The juvenile transition: A developmental switch point in human life history. Developmental Review, 29, 1-31.

Dierkes, P., Heg, D., Taborsky, M., Skubic, E. \& Achmann, R. 2005. Genetic relatedness in groups is sex-specific and declines with age of helpers in a cooperatively breeding cichlid. Ecology Letters, 8, 968-975.

Dirks, M.A., Treat, T.A. \& Weersing, V.R. 2007. Integrating theoretical, measurement, and intervention models of young social competence. Clinical Psychology Review, 27, 327-347.

Duftner, N., Sefc, K.M., Koblmüller, S. Salzburger, W., Taborsky, M. \& Sturmbauer, C. 2007. Parallel evolution of facial stripe patterns in the Neolamprologus brichardi/pulcher species complex endemic to Lake Tanganyika. Molecular Phylogenetics and Evolution, 45, 706-715.

Earley, R.L., Edwards, J.T., Aseem, O., Felton, K., Blumer, L.S., Karom, M. \& Grober, M.S. 2006. Social interactions tune aggression and stress responsiveness in a territorial cichlid fish (Archocentrus nigrofascitatus). Physiology and Behavior, 88, 353-363.

Faraway, J.J. (2006): Extending the Linear Model with R. Boca Raton, Florida: Chapman \& Hall/CRC.

Frazier, C.R.M., Trainor, B.C., Cravens, C.J., Whitney, T.K. \& Marler, C.A. 2006. Parental behaviour influences development of aggression and vasopressin expression in male California mouse offspring. Hormones and Behavior, 50, 699-707.

Grantner, A., Taborsky, M. 1998. The metabolic rates associated with resting, and with the performance of agonistic, submissive and digging behaviours in the cichlid fish Neolamprologus pulcher (Pisces:Cichidae). Journal of Comparative Physiological Biology, 168, 427-433.

Heg, D., Bachar, Z., Brouwer, L. \& Taborsky, M. 2004. Predation risk is an ecological constraint for helper dispersal in a cooperatively breeding cichlid. Proceedings of the Royal Society B, 271, 2367-2374.

Hirschenhauser, K., Canario, A.V.M., Ros, A.F.H., Taborsky, M. \& Oliveira, R.F. 2008. Social context may affect urinary excretion of 11-ketotestosterone in African cichlids. Behaviour, 145, 1367-1388.

Jentoft, S., Aastveit, A.H., Torjesen, P.A. \& Andersen, O. 2005. Effects of stress on growth, cortisol and glucose levels in non-domesticated Eurasian perch (Perca fluviatilis) and domesticated rainbow trout (Oncorhynchus mykiss). Comparative Biochemistry and Physiology A, 141, 353-358 
Kelley, J.L. \& Magurran, A.E. 2003. Learned predator recognition and antipredator responses in fishes. Fish and Fisheries, 4, 216-226.

Kempes, M.M., Gulickx, M.M.C., van Daalen, H.J.C., Louwerse, A.L. \& Sterck, E.H.M. 2008. Social competence is reduced in socially deprived rhesus monkeys (Macaca mulatta). Journal of Comparative Psychology, 122, 62-67.

Laviola, G. and Terranova, M.L. 1998. The developmental psychobiology of behaviour plasticity in mice: the role of social experience in the family unit. Neuroscience and Biobehavioural Reviews, 23, 197-213.

Levine, S. \& Mody, T. 2003. The long-term psychobiological consequences of intermittent postnatal separation in the squirrel monkey. Neuroscience and Biobehavioral Reviews, 27, 83-89.

Lévy, F., Melo, A.I., Galef, Jr. B.G., Madden, M. \& Flemming, A.S. 2003. Complete maternal deprivation affects social, but not spatial learning in adult rats. Developmental Psychobiology, 43, 177-191.

Meaney, M.J. \& Szyf, M. 2005. Maternal care as a model for experience-dependent chromatin plasticity? Trends in Neuroscience, 28, 456-463.

Margulis, S.W., Nabong, M., Alaks, G., Walsh, A. \& Lacy, R.C. 2005. Effects of early experience on subsequent parental behaviour and reproductive success in oldfield mice, Peromyscus polionotus. Animal Behaviour, 69, 627-634.

Mitchell, J.S., Jutzeler, E., Heg, D. \& Taborsky, M. in press. Dominant members of cooperativelybreeding groups adjust their behaviour in response to the sexes of their subordinates. Behaviour.

Moretz, J.A., Martins, E.P. \& Robison, B.D. 2007. The effect of early and adult social environment on zebrafish (Danio rerio) behavior. Environmental Biology of Fishes, 80, 91-101.

Niles, M.D., Reynolds, A.J., Roe-Sepowitz, D. 2008. Early childhood intervention and early adolescent social and emotional competence: second-generation evaluation evidence from the Chicago Longitudinal study. Educational Research, 50, 55-73.

Pinto, W., Aragao, C., Soares, F., Dinis, M.T. \& Conceicao, L.E.C. 2007. Growth, stress response and free amino acid levels in Senegalese sole (Solea senegalensis Kaup 1858) chronically exposed to exogenous ammonia. Aquaculture Research, 38, 1198-1204.

R Development Core Team 2006. R: A Language and Environment for Statistical Computing. R Foundation for Statistical Computing, Vienna, Austria.

Taborsky, M. \& Limberger, D. 1981. Helpers in fish. Behavioural Ecology and Sociobiology, 8, 143-145.

Taborsky, M. 1982. Brutpflegehelfer beim Cichliden Lamprologus brichardi, Poll (1974): eine Kosten/Nutzen-Analyse. PhD Thesis, University of Vienna.

Taborsky M. 1984. Broodcare helper in the cichlid fish Lamprologus brichardi: their costs and benefits. Animal Behaviour, 32, 1236-1252.

Taborsky, M. 1985. Breeder-helper conflict in a cichlid fish with broodcare helpers: an experimental analysis. Behaviour, 95, 45-75.

Verzijden, M.N. \& ten Cate, C. 2007. Early learning influences species assortative mating preferences in Lake Victoria cichlid fish. Biology Letters, 3, 134-136. 
Werner, Y.N., Balshine, S., Leach, B. \& Lotem, A. 2003. Helping opportunities and space segregation in cooperatively breeding cichlids. Behavioral Ecology, 14, 749-756. 
Table 1. Linear mixed-effects models (LME) to test for the effect of treatment and a potential interaction of treatment and repeat on standard length. Breeding pair and clutch were included as random effects. The comparisons between the treatments $-\mathrm{F}$ (i.e. $-\mathrm{B}$ and $-\mathrm{BH}$ ), $+\mathrm{B}$ and $+\mathrm{BH}$ are done over all repeats, as the model with interaction of treatment and repeat did not fit the data significantly better than a model without this interaction. Sample sizes are given for repeated measurements, clutches and breeding pairs (significant p-values are highlighted in bold).

\begin{tabular}{ccrrr}
\hline $\begin{array}{c}\text { model } \\
\text { comparisons }\end{array}$ & $\mathrm{N}_{\text {meas }}, \mathrm{N}_{\text {clutch }}, \mathrm{N}_{\text {brood }}$ & \multicolumn{1}{c}{$\chi^{2}$} & df & \multicolumn{1}{c}{$\mathrm{p}$} \\
\hline treatment & $986,12,6$ & 52.70 & 2 & $<\mathbf{0 . 0 0 1}$ \\
treat $\times$ repeat & $986,12,6$ & 1.44 & 2 & 0.488 \\
+B vs. $-\mathrm{F}$ & $737,12,6$ & 1.37 & 1 & 0.24 \\
+BH vs. $-\mathrm{F}$ & $737,12,6$ & 52.67 & 1 & $<\mathbf{0 . 0 0 1}$ \\
+B vs. + BH & $498,12,6$ & 1.93 & 1 & 0.16 \\
\hline
\end{tabular}


Table 2. Generalized linear mixed-effects models (GLMM) to test for treatment and repeat effects on aggressive behaviour of fry. Breeding pair and clutch were included as random effects. Models for treatment within each repeat were calculated. Only in repeat 4 the model including treatment fitted the data significantly better than the model without treatment. Comparisons of aggression within repeat 4 were done to test which differences between treatments are responsible for the overall treatment effect. Significant p-values are shown in bold numbers $(\alpha$-level=0.017 after sequential Bonferroni correction). Sample sizes given for observations, clutches and breeding pairs.

\begin{tabular}{lcccc}
\hline \multicolumn{1}{c}{ model comparisons } & $\mathrm{N}_{\text {obs }}, \mathrm{N}_{\text {clutch }}, \mathrm{N}_{\text {pair }}$ & $\chi^{2}$ & $\mathrm{df}$ & $\mathrm{p}$ \\
\hline treat $\times$ repeat & $680,12,6$ & 22.06 & 6 & $\mathbf{0 . 0 0 1 2}$ \\
treat in repeat 1 & $170,12,6$ & 4.78 & 2 & 0.092 \\
treat in repeat 2 & $170,12,6$ & 0.29 & 2 & 0.87 \\
treat in repeat 3 & $170,12,6$ & 1.51 & 2 & 0.47 \\
treat in repeat 4 & $170,12,6$ & 17.20 & 2 & $\mathbf{0 . 0 0 0 1 8}$ \\
+B vs. $-\mathrm{F}$ (repeat 4) & $125,12,6$ & 10.45 & 1 & $\mathbf{0 . 0 0 1 2}$ \\
+ BH vs. $-\mathrm{F}$ (repeat 4) & $130,12,6$ & 11.61 & 1 & $\mathbf{0 . 0 0 0 6 5}$ \\
+ B vs. +BH (repeat 4) & $85,12,6$ & 0.03 & 1 & 0.86 \\
\hline
\end{tabular}


Table 3: Frequency of submissive behaviour (clutch means) in sequential repeats during the social experience phase compared between fish raised with $(+\mathrm{F})$ or without $(-\mathrm{F})$ older family members. When analysing the data separately by treatments without $(+\mathrm{B} /-\mathrm{B})$ or with helper $(+\mathrm{BH} /-\mathrm{BH})$ the differences in the older fry (repeat 3 and 4$)$ are only partly retained due to a lower power or these tests. Data were analyzed by non-parametric statistics as they were considerably zero-inflated (Wilcoxon signed-ranks tests).

\begin{tabular}{ccccccccccc}
\hline & \multicolumn{3}{c}{+ F vs. $-\mathrm{F}$} & \multicolumn{3}{c}{+ B vs. $-\mathrm{B}$} & \multicolumn{3}{c}{+ BH vs. $-\mathrm{BH}$} \\
\cline { 2 - 10 } & $\mathrm{z}$ & $\mathrm{p}$ & $\mathrm{N}$ & $\mathrm{z}$ & $\mathrm{p}$ & $\mathrm{N}$ & $\mathrm{z}$ & $\mathrm{p}$ & $\mathrm{N}$ \\
\hline repeat 1 & 1.60 & 0.109 & 12 & 1.34 & 0.18 & 6 & 1.00 & 0.32 & 6 \\
repeat 2 & 1.21 & 0.228 & 12 & 0.37 & 0.71 & 6 & 1.47 & 0.14 & 6 \\
repeat 3 & 2.85 & $\mathbf{0 . 0 0 4}$ & 12 & 1.84 & 0.066 & 6 & 2.26 & $\mathbf{0 . 0 2 4}$ & 6 \\
repeat 4 & 2.05 & $\mathbf{0 . 0 4 1}$ & 12 & 1.60 & 0.11 & 6 & 1.84 & 0.066 & 6 \\
\hline
\end{tabular}


Table 4. Linear mixed-effect models to test for effects of treatment (+B vs. $+\mathrm{BH})$ and repeat on aggressive behaviour among all older family members and among breeders only. Identity of breeder pair was included as random effect; $\mathrm{N}=12$.

\begin{tabular}{lcccccc}
\hline & \multicolumn{3}{c}{ all older family members } & \multicolumn{3}{c}{ breeders } \\
\cline { 2 - 7 } & df & $\mathrm{F}$ & $\mathrm{p}$ & $\mathrm{df}$ & $\mathrm{F}$ & $\mathrm{p}$ \\
\hline treatment & 1 & 8.73 & $\mathbf{0 . 0 0 6}$ & 1 & 4.42 & $\mathbf{0 . 0 3 5}$ \\
repeat & 3 & 0.49 & 0.69 & 3 & 1.21 & 0.29 \\
treat $\times$ repeat & 3 & 0.72 & 0.55 & 3 & 0.91 & 0.42 \\
\hline
\end{tabular}


Table 5. Behaviours of intruders (I) and shelter owners (S) in the social performance test. Focal fish with different social experience (+F, $-\mathrm{F})$ are compared; significant p-values are highlighted in bold.

\begin{tabular}{|c|c|c|c|c|c|c|c|c|c|c|}
\hline \multirow[t]{3}{*}{ behaviour } & \multirow{3}{*}{$\begin{array}{l}\text { focal } \\
\text { fish }\end{array}$} & \multirow{2}{*}{\multicolumn{3}{|c|}{ Wilcoxon tests }} & \multicolumn{6}{|c|}{ Mann-Whitney U-tests } \\
\hline & & & & & \multicolumn{3}{|c|}{ opponent is $+\mathrm{F}$} & \multicolumn{3}{|c|}{ opponent is $-\mathrm{F}$} \\
\hline & & $\mathrm{z}$ & $\mathrm{p}$ & $\mathrm{N}$ & $\mathrm{U}$ & $\mathrm{p}$ & $\mathrm{N}$ & $\mathrm{U}$ & $\mathrm{p}$ & $\mathrm{N}$ \\
\hline rates of submission & I & 2.68 & 0.007 & 31 & 53.0 & 0.045 & 24,8 & 91.0 & 0.85 & 24,8 \\
\hline submission/aggression & $\mathrm{I}$ & 2.57 & 0.01 & 32 & 52.0 & 0.055 & 23,8 & 90.0 & 0.81 & 24,8 \\
\hline rates of threat display & S & 3.30 & 0.001 & 31 & 31.5 & 0.005 & 24,8 & 66.5 & 0.20 & 24,8 \\
\hline rates of open aggression & $S$ & 0.81 & 0.32 & 31 & 85.5 & 0.65 & 24,8 & 83.0 & 0.57 & 24,8 \\
\hline$\%$ threat display & $S$ & 2.80 & 0.005 & 31 & 42.0 & 0.018 & 24,8 & 68.0 & 0.28 & 23,8 \\
\hline duration of contest & $S$ & & & & 35.5 & 0.018 & 21,8 & 51.5 & 0.27 & 24,6 \\
\hline
\end{tabular}




\section{Figures}

Figure 1: Experimental set-up indicating the different phases and timeline of the experiment. During the larval stage and the $+\mathrm{F}$ treatment of the social experience phase, in half of the trial only the parents were present $(+\mathrm{B}$; depicted in sketch), in the other trials the parents and two brood care helpers were present $(+\mathrm{BH})$. Large digits: onset of experimental phases; black triangles and small digits: day of behavioural observations during social experience phase; open triangles and small digits: days of size measurements.

Figure 2. Mean standard length of fry $( \pm \mathrm{SE})$ from different raising conditions. Black: fry raised alone: $\mathrm{N}=12,-\mathrm{B}$ and $-\mathrm{BH}$ combined; dark grey: $+\mathrm{B}, \mathrm{N}=6$; light grey: $+\mathrm{BH}, \mathrm{N}=6$. Stippled line indicates time when holding conditions were changed (day 62).

Figure 3: Behaviour of fry at four repeated observations during the social experience phase (medians and quartiles). Black: $+\mathrm{F}$ fry; grey: $-\mathrm{F}$ fry. (a) Frequencies of total aggression; (b) frequencies of submissive behaviour. Asterisks indicate significant differences.

Figure 4. Behaviour of juveniles during the social performance test in dependence of the raising conditions of the opponent (medians and quartiles). Black: $+\mathrm{F}$ fish; grey: $-\mathrm{F}$ fish; on top of each panel the social experience of the opponent is noted; 'with' / 'without' = raised with / without older conspecifics. (a) Rate of submissive behaviour by intruders, (b) ratio of submission shown by intruders per received total aggression, (c) rates of threat displays by shelter owner, (d) duration of contest (treatment of shelter owner on abscissa). 


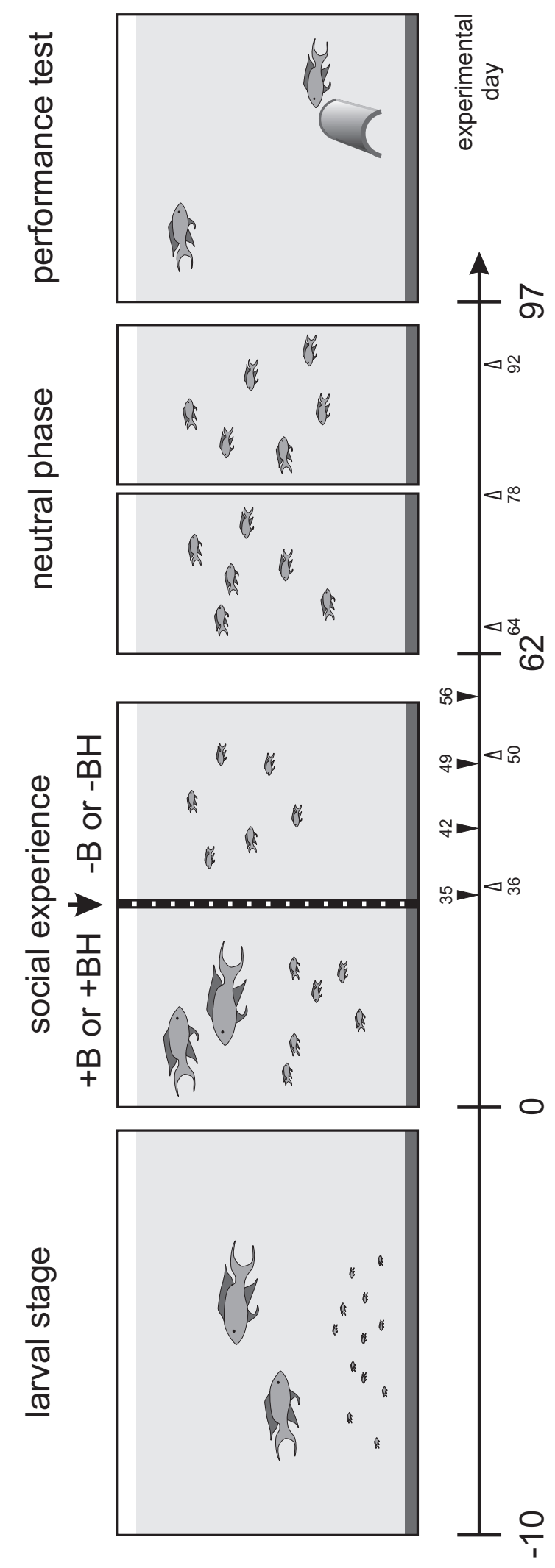

Figure 


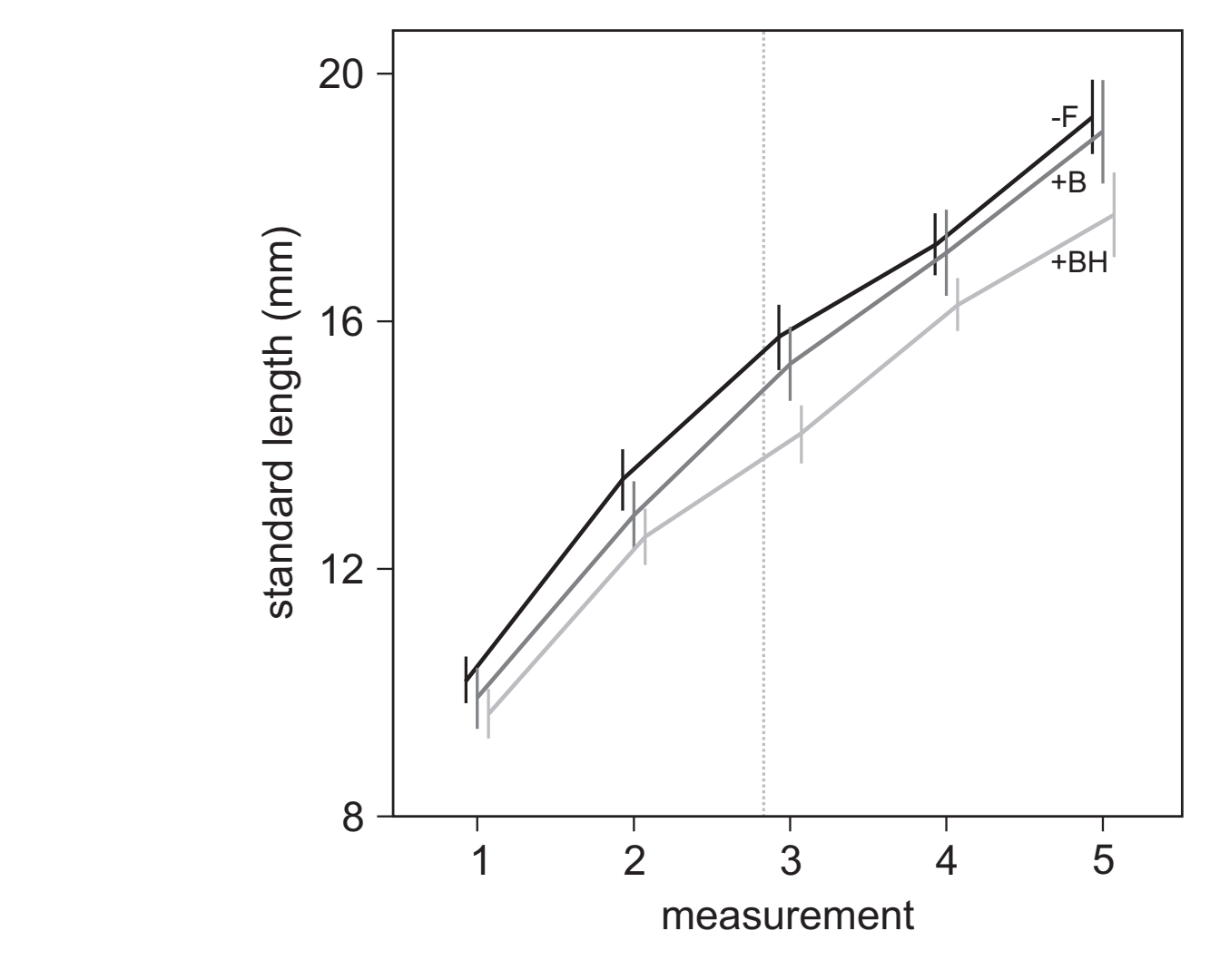

Figure

.

.

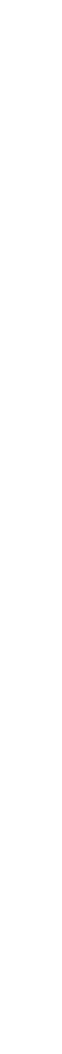



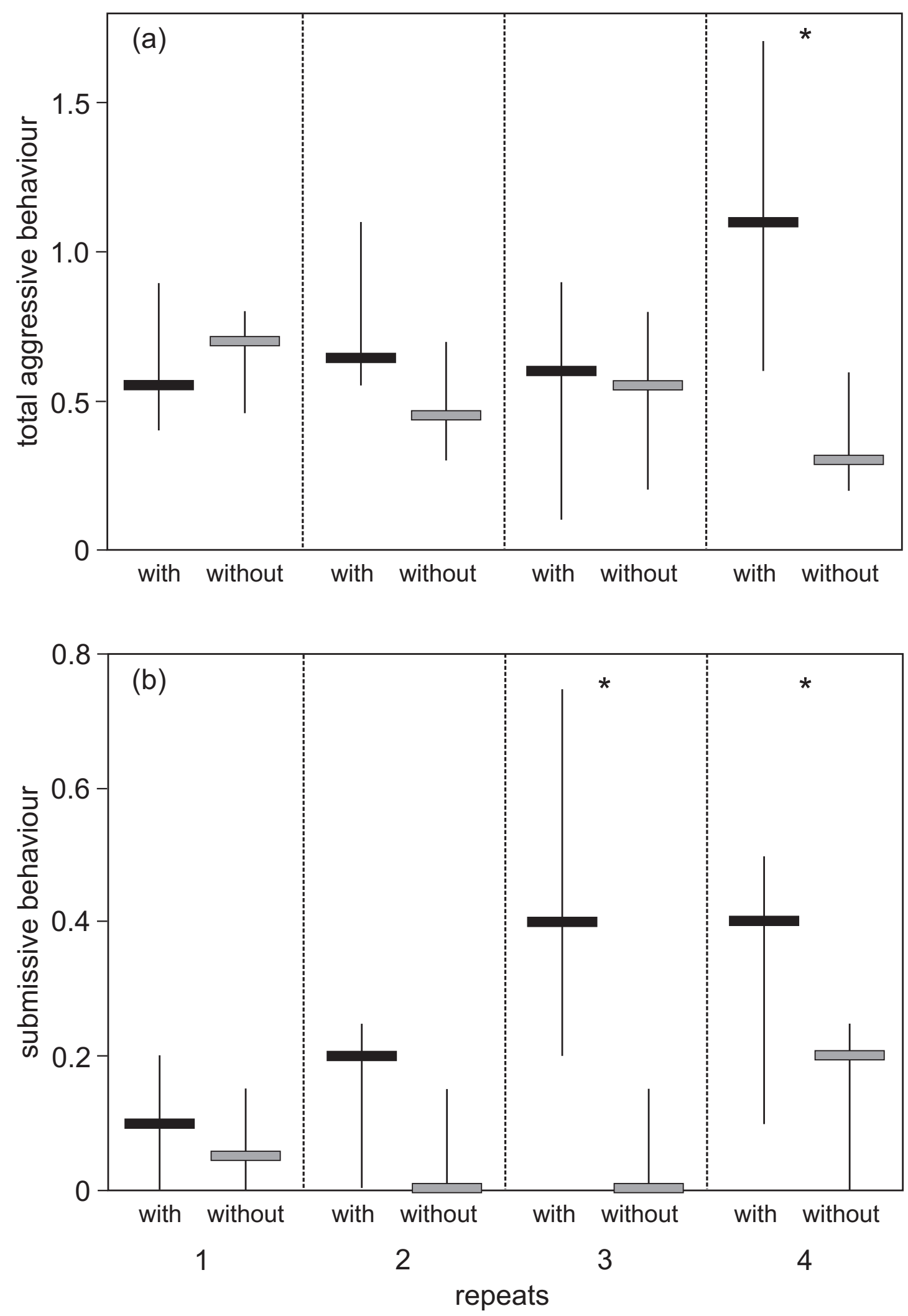

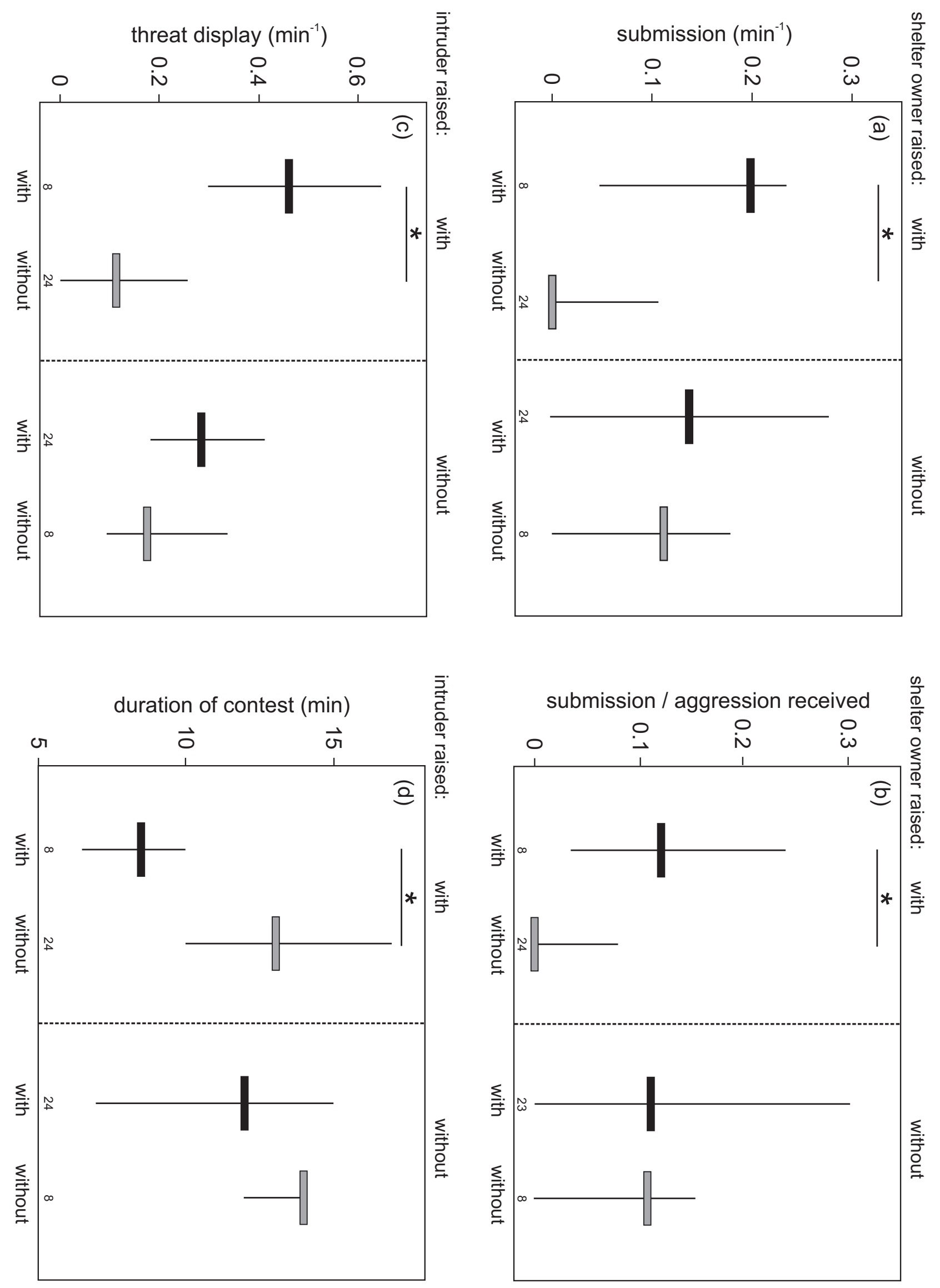